\title{
HEMATOLOGICAL PARAMETERS AND MORPHOLOGICAL ALTERATIONS IN LEUCOCYTES OF COVID-19 PATIENTS
}

\begin{tabular}{ll}
\hline Pathology & \\
$\begin{array}{ll}\text { Dr. Prashant S } \\
\text { Murarkar }\end{array}$ & Associate Professor Department of Pathology, Government Medical College and \\
\hline Dr.(Mrs)Alka & Associate Professor Department of Pathology, Government Medical College and \\
Vikas Gosavi & Hospital, Miraj, Maharashtra, India. \\
\hline $\begin{array}{ll}\text { Dr. Amruta } \\
\text { Shankar Jujgar* }\end{array}$ & Assistant Professor Department of Pathology, Government Medical College and \\
\hline Dr. Priyanka & Junior Resident III Department of Pathology, Government Medical College and Hospital, \\
Sanjay Patil & Miraj, Maharashtra, India.
\end{tabular}

\section{ABSTRACT}

World Health Organization (WHO) announced COVID-19 outbreak as a pandemic on 11th March 2020. COVID-19 caused its impact globally with a substantial morbidity and mortality in people across the world especially in those at a higher age group with comorbidities. Most of the organ systems are affected including hematopoietic system. We studied the hematological profile of 196 confirmed COVID-19 positive patients at our tertiary care center from 22nd March 2020 to 15th June 2020. Various hematological parameters including Haemoglobin(Hb), Total Leucocyte Count(TLC), Absolute Neutrophil count(ANC), Absolute Lymphocyte Count(ALC), Absolute Monocyte Count(AMC), Absolute Eosinophil Count(AEC), Platelet Count(PC), Neutrophil to Lymphocyte Ratio(NLR), Erythrocyte Sedimentation Rate(ESR) and Peripheral blood smears were studied. We found $\mathrm{Hb}$ levels were decreasing in the patients with more severe disease. Leucopenia, lymphopenia, eosinopenia, neutrophilia, raised ESR and increasing NLR was seen in patients with more severe disease and those who succumbed to death. We also observed various morphological abnormalities in leucocytes in peripheral blood films of these patients. These parameters prove their prognostic significance in risk stratification in the COVID-19 positive patients for early intervention and deciding treatment regimens which may help to alleviate the morbidity and mortality. As these tests are easily available even at low resource settings, in developing country like India this study may help the patients who are being treated at peripheral centers to get referred to a higher center and get better treatment to reduce the morbidity and mortality.

\section{KEYWORDS}

COVID-19, Lymphopenia, Eosinopenia, Neutrophil to Lymphocyte Ratio.

\begin{abstract}
INTRODUCTION
One of the largest pandemics of the century hitting the world marked its beginning on 31 December 2019 at Wuhan, China where a cluster of unexplained pneumonia cases were reported ${ }^{1}$. The causative agent for this outbreak was named severe acute respiratory syndrome coronavirus 2 (SARS-CoV-2), which was responsible for the Corona Virus Disease 2019 (COVID-19) ${ }^{1}$. India confirmed its first case on $30^{\text {th }}$ January $2020^{2}$. The first case of COVID-19 in Maharashtra was detected on $9^{\text {th }}$ March $2020^{2}$. Our hospital admitted the first case of COVID-19 on $22^{\text {nd }}$ March 2020.
\end{abstract}

Coronaviruses are enveloped virions with longest positive sense ribonucleic acid (RNA) genome ${ }^{3}$. SARS-CoV-2 appears to have been a zoonotic infection that has adapted to humans. SARS-CoV-2 virus primarily affects the respiratory system, although other organ systems like hematopoietic system is also involved. ${ }^{4}$

Evaluation of hematological parameters in COVID-19 play a very crucial role in determining the prognosis. Lymphopenia is a common finding in affected patients and has a significant adverse prognostic value. $^{5} \quad$ Complete blood count(CBC) is a common laboratory investigation that is being performed even at low resource settings, which also predicts the severity of SARS-CoV-2 infection and thereby help the clinician to intervene and reduce the mortality rate.

\section{MATERIALS AND METHOD}

This study was a retrospective study which included 196 confirmed cases of COVID-19, diagnosed on nasopharyngeal swab by Reverse Transcriptase-Polymerase Chain Reaction (RT-PCR) admitted at Government Medical College and Hospital, Miraj from $22^{\text {nd }}$ March 2020 to $15^{\text {th }}$ June 2020. We received blood samples in K2-EDTA anticoagulated tubes for $\mathrm{CBC}$ and ESR. Blood samples received for CBC were processed on automated SYSMEX XN-550 hematology analyzer. ESR was done by Westergren's method. Peripheral blood films were prepared and stained by leishman's stain. We studied the hematological parameters including Hemoglobin $(\mathrm{Hb})$, Total Leucocyte Count (TLC), Absolute Neutrophil Count (ANC), Absolute Lymphocyte Count (ALC), Absolute Monocyte Count (AMC), Absolute Eosinophil Count (AEC), Platelet count and Erythrocyte sedimentation rate (ESR) of the admitted patients. We also reviewed the peripheral blood films of all the patients. Other data includes the demographics.

We divided the patients into three groups: patients admitted in Intensive care unit (ICU), non-ICU patients and those who succumbed to death (non-survivors).

\section{RESULTS}

We received samples of 196 confirmed cases of COVID-19 patients for CBC. Out of these samples 178 patients were from the non-ICU group, 9 cases were admitted in the ICU and 9 patients succumbed to death(Non-survivors) due to severe SARS-CoV-2 infection.

In the present study the youngest patient was 8 -year-old boy and the oldest was 96-year-old woman. The age distribution of 196 COVID-19 patients is given in Table-1

Table 1: Age distribution of COVID-19 patients

\begin{tabular}{|c|c|c|c|}
\hline Age group & Non-ICU & ICU & Non-Survivors \\
\hline$</=10$ years & 5 & 0 & 0 \\
\hline $11-20$ years & 16 & 0 & 0 \\
\hline $21-30$ years & 32 & 1 & 0 \\
\hline $31-40$ years & 29 & 1 & 0 \\
\hline $41-50$ years & 32 & 2 & 3 \\
\hline 51-60 years & 34 & 3 & 3 \\
\hline 61-70 years & 21 & 1 & 2 \\
\hline$>70$ years & 9 & 1 & 1 \\
\hline Total & 178 & 9 & 9 \\
\hline
\end{tabular}

The mean age among the Non - ICU group was 43.4 years and among the ICU was 53 years, while among the non-survivors 58.7 years was the mean age found. Among all the groups there were 72 female and 124 male patients. (Figure 1) 


\section{FIGURE 1}

MALE FEMALE

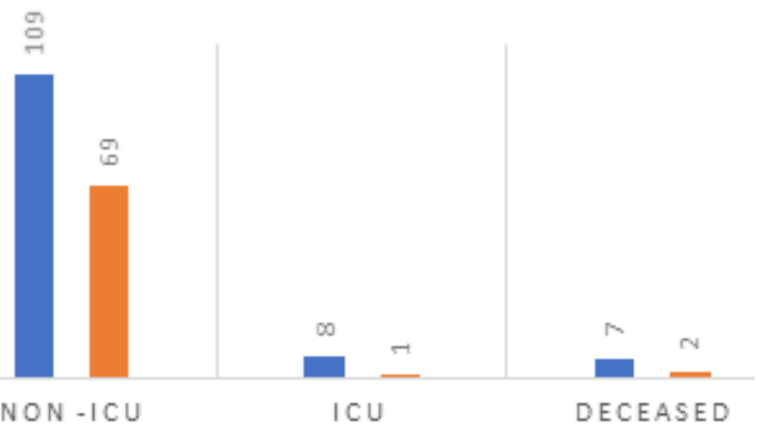

Figure 1: Sex distribution of Non-ICU, ICU and non-survivor group

We compared the hematological parameters between Non-ICU, ICU and non-survivors group. Table 2 shows the mean Hb, TLC, ANC, $\mathrm{ALC}, \mathrm{AMC}, \mathrm{AEC}$ and Platelet count of all the groups.

Table 2: Comparison of hematological parameters between NonICU, ICU and Non-survivor group

\begin{tabular}{|l|l|l|l|}
\hline & Non-ICU(n-178) & ICU(n-9) & Non-survivors(n-9) \\
\hline $\mathrm{Hb}$ g/dl & 12.8 & 11.8 & 11.1 \\
\hline $\mathrm{TLC} / \mu \mathrm{l}$ & 5671 & 8730 & 7720 \\
\hline $\mathrm{ANC} / \mu \mathrm{l}$ & 3479 & 7904 & 6733 \\
\hline $\mathrm{ALC} / \mu \mathrm{l}$ & 1834 & 681 & 759 \\
\hline $\mathrm{AMC} / \mu \mathrm{l}$ & 223 & 130 & 134 \\
\hline $\mathrm{AEC} / \mu \mathrm{l}$ & 134 & 7.7 & 8.8 \\
\hline $\mathrm{PC} \times 103 / \mu \mathrm{l}$ & 241 & 224 & 246 \\
\hline
\end{tabular}

$\mathrm{Hb}$ - Hemoglobin, TLC - Total Leucocyte count, ANC -Absolute Neutrophil Count, ALC - Absolute Lymphocyte Count, AMCAbsolute Monocyte Count, AEC- Absolute Eosinophil Count PC Platelet Count.

Mean hemoglobin among the Non-ICU group was $12.8 \mathrm{gm} \%$, among the ICU group $11.8 \mathrm{gm} \%$ and among the non-survivors the mean $\mathrm{Hb}$ values again decreased to $11.1 \mathrm{gm} \%$. Mean ANC was seen to be raised among the ICU patients when compared to Non-ICU patients. Comparing the ALC among all the groups $1834 / \mu 1,681 / \mu 1$ and $759 / \mu 1$ were the ALC in Non-ICU, ICU and the non-survivors group respectively. $\mathrm{ALC}<1000 / \mu 1$ is considered as lymphopenia. Lymphopenia was seen among the ICU patients and non-survivors. AMC $<200 / \mu 1$ is considered as monocytopenia which was found in ICU patients and non-survivors. The mean platelet count was seen to be normal in all the groups in our study.

In the present study, we studied and evaluated AEC of all 196 COVID19 patients of which 57 patients showed eosinopenia. 43(24\%) out of 178 patients from non-ICU and 7(77.7\%) out of 9 each from ICU and non-survivors groups showed eosinopenia. While $17(9.5 \%)$ patients from non-ICU and 7(77.7\%) each from ICU and non-survivors group had AEC $0 / \mu 1$. Rest of the patients showed AEC within normal range. $\mathrm{AEC}<20 / \mu 1$ is considered as eosinopenia. When mean AEC was taken into account, eosinopenia was seen in ICU and non-survivor groups of COVID-19 positive patients in our study. AEC returned to normal at the time of discharge.

Total Leucocyte Count $<4000$ was considered as Leucopenia.

Table 3: Comparison of Total Leucocyte Count and Absolute Lymphocyte Count between Non-ICU, ICU and Non-survivors group

\begin{tabular}{|c|c|c|c|c|c|c|c|}
\hline & & \multicolumn{2}{|c|}{ Non-ICU } & \multicolumn{2}{|c|}{ ICU } & \multicolumn{2}{|c|}{ Non-survivors } \\
\hline & TLC & $\begin{array}{l}\text { No. of } \\
\text { cases }\end{array}$ & $\%$ & $\begin{array}{c}\text { No. of } \\
\text { cases }\end{array}$ & $\%$ & $\begin{array}{l}\text { No. of } \\
\text { cases }\end{array}$ & $\%$ \\
\hline \multirow{3}{*}{\begin{tabular}{|c|} 
Total \\
Leucocyte \\
Count
\end{tabular}} & $<2$ X109/L & 1 & $0.5 \%$ & 0 & $0 \%$ & 0 & $0 \%$ \\
\hline & $\begin{array}{l}2-4 X \\
109 / \mathrm{L}\end{array}$ & 34 & $19.1 \%$ & 2 & $22.22 \%$ & 1 & $11.11 \%$ \\
\hline & $>4 X 109 / \mathrm{L}$ & 143 & $80.4 \%$ & 7 & $77.78 \%$ & 8 & $88.89^{\circ}$ \\
\hline \multirow{3}{*}{\begin{tabular}{|l|} 
Absolute \\
Lymphoc \\
yte Count
\end{tabular}} & $\begin{array}{l}<0.5 X \\
109 / \mathrm{L}\end{array}$ & 2 & $1.1 \%$ & 5 & $55.56 \%$ & 2 & 22.22 \\
\hline & \begin{tabular}{|c|}
$0.5-1.0 \mathrm{X}$ \\
$109 / \mathrm{L}$
\end{tabular} & 18 & $10.1 \%$ & 2 & $22.22 \%$ & 5 & $55.56^{\circ}$ \\
\hline & $\begin{array}{l}>1.0 \mathrm{X} \\
109 / \mathrm{L}\end{array}$ & 158 & $88.8 \%$ & 2 & $22.22 \%$ & 2 & .22 \\
\hline
\end{tabular}

Leucopenia was seen in 38 patients consisting of 35 (19.6\%) patients among the Non-ICU group, $2(22.2 \%)$ patients among the ICU and $1(11.1 \%)$ from the non-survivors group. (Table 3). Among nonsurvivors and ICU $7(77.7 \%)$ patients each showed Lymphopenia and only $20(11 \%)$ patients among Non-ICU group had an ALC $<1 \times 10^{9} / \mathrm{L}$.

Neutrophil-to-lymphocyte ratio (NLR) in peripheral blood could be studied as a systemic inflammatory marker that can be easily calculated from the $\mathrm{CBC}$ report of the patient. NLR is used as a marker of subclinical inflammation. It is calculated by dividing absolute neutrophil count by absolute lymphocyte count.

Table 4 shows Comparison of Age wise distribution of Absolute Lymphocyte Count and NLR among Non-ICU, ICU and non-survivors group.

\begin{tabular}{|c|c|c|c|c|c|c|c|c|c|c|c|c|c|c|c|}
\hline & \multicolumn{5}{|c|}{$\begin{array}{c}\text { Non-ICU } \\
(n-178)\end{array}$} & \multicolumn{5}{|c|}{$\begin{array}{l}\text { ICU } \\
(\mathrm{n}-9)\end{array}$} & \multicolumn{5}{|c|}{$\begin{array}{c}\text { Non-survivors } \\
(n-9)\end{array}$} \\
\hline & Absolu & te Lymphoc & te Count & $\mathrm{N}: \mathrm{L}$ & Ratio & Absolut & te Lymphocy & te Count & $\mathrm{N}: \mathrm{L}$ & Ratio & Absol & ute Lympho & yte Count & $\mathrm{N}: \mathrm{LI}$ & Ratio \\
\hline Age group & $\begin{array}{c}>1000 \\
/ \mu 1\end{array}$ & $\begin{array}{c}500-1000 \\
/ \mu 1\end{array}$ & $\begin{array}{c}<500 \\
/ \mu 1\end{array}$ & $<3.33$ & $>3.33$ & $\begin{array}{c}>1000 \\
/ \mu 1\end{array}$ & $\begin{array}{c}500-1000 \\
/ \mu 1\end{array}$ & $\begin{array}{c}<500 \\
/ \mu 1\end{array}$ & $<3.33$ & $3>3.33$ & $\begin{array}{c}>1000 \\
/ \mu 1\end{array}$ & $\begin{array}{c}500-1000 \\
/ \mu 1\end{array}$ & $\begin{array}{c}<500 \\
/ \mu 1\end{array}$ & $<3.33$ & $>3.33$ \\
\hline$</=10$ years & 5 & 0 & 0 & 5 & 0 & 0 & 0 & 0 & 0 & 0 & 0 & 0 & 0 & 0 & 0 \\
\hline $11-20$ years & 15 & 1 & 0 & 13 & 3 & 0 & 0 & 0 & 0 & 0 & 0 & 0 & 0 & 0 & 0 \\
\hline 21-30 years & 30 & 2 & 0 & 29 & 4 & 0 & 0 & 1 & 0 & 1 & 0 & 0 & 0 & 0 & 0 \\
\hline $31-40$ years & 27 & 1 & 0 & 26 & 1 & 1 & 0 & 0 & 0 & 1 & 0 & 0 & 0 & 0 & 0 \\
\hline $41-50$ years & 27 & 4 & 1 & 28 & 4 & 0 & 1 & 1 & 0 & 2 & 1 & 1 & 0 & 0 & 2 \\
\hline 51-60 years & 28 & 5 & 1 & 28 & 8 & 1 & 1 & 1 & 0 & 3 & 0 & 2 & 2 & 0 & 4 \\
\hline $61-70$ years & 19 & 2 & 0 & 15 & 5 & 0 & 0 & 1 & 0 & 1 & 1 & 1 & 0 & 0 & 2 \\
\hline$>70$ years & 7 & 3 & 0 & 6 & 3 & 0 & 0 & 1 & 0 & 1 & 0 & 1 & 0 & 0 & 1 \\
\hline
\end{tabular}

Increase in NLR and Lymphopenia was observed in all the groups with increasing age. Among the Non-ICU patients, comparing the age groups affected, there were no patients below 10 years with ALC $<1000 / \mu 1$. Maximum number of patients with ALC $<1000 / \mu 1$ were found in age group of 40-60 years. We obtained similar results among the ICU and non-survivors group. Severe lymphopenia was found in $5(55.5 \%)$ patients in ICU group. When NLR was compared among the various age groups NLR $>3.33$ was observed with increasing age in all the groups. Among all the groups maximum number of patients with NLR $>3.33$ were found in age group $>40$ years. (Table 4)

We also compared the mean Neutrophil-Lymphocyte ratio (NLR) among all the groups on the day of admission, between 5-8 days of admission and at the time of discharge. (Table 5)

Table 5: Comparison of NLR in Non-ICU, ICU and non-survivors group

\begin{tabular}{|l|l|l|l|}
\hline Mean N/L Ratio & Non-ICU & ICU & Non-survivors \\
\hline At the time of admission & 2.42 & 14.46 & 11.36 \\
\hline Day 5-8 & 4.68 & 24.98 & - \\
\hline $\begin{array}{l}\text { Day of discharge/ } \\
\text { Last available report }\end{array}$ & 1.75 & 13.34 & - \\
\hline
\end{tabular}

NLR was more in ICU group as compared to Non-ICU group. Among the non-survivors group the mean NLR was available only at the time 
of admission and that was found to 11.36 which was more than the nonICU group.

We received 114 samples for ESR consisting of 104 samples from the Non-ICU group, and 5 each from the ICU and non-survivors group. The mean ESR was 38.03, 59.6 and $40 \mathrm{~mm}$ at the end of one hour in Non-ICU, ICU and non-survivors group respectively (Table 6). We found raised ESR in all the groups.

Table 6: Comparison of Mean ESR among Non-ICU, ICU and Non-survivors group

\begin{tabular}{|l|l|l|l|}
\hline & Non-ICU (n-104) & ICU (n-5) & Non-survivors(n-5) \\
\hline $\begin{array}{l}\text { Mean } \\
\text { ESR(mm/hr) }\end{array}$ & 38.03 & 59.6 & 40 \\
\hline
\end{tabular}

ESR-Erythrocyte Sedimentation Rate

We also reviewed the peripheral blood films of all the COVID-19 positive patients, which revealed various morphologic abnormalities in different leucocytes. The neutrophils in some cases showed wide variations in their nuclei which include ring forms, C-shaped nuclei, hypolobated nuclei and few of them were apoptotic. We also observed increased coarse granules in the cytoplasm of neutrophils and cytoplasmic vacuoles, while in few cases the cytoplasm of neutrophils were hypogranular. Some of the lymphocytes had abundant pale blue cytoplasm, the nuclei showed coarse chromatin with indistinct nucleoli-reactive lymphocytes. Some of the lymphocytes showed cytoplasmic pseudopod formation. Few lymphocytes were having abundant cytoplasm with granules in it - Large granular lymphocyte. Some showed nuclear granules. Other findings were presence of reactive/activated monocyte showing few cytoplasmic granules and vacuoles. In 31 patients no eosinophils were detected in peripheral smear.

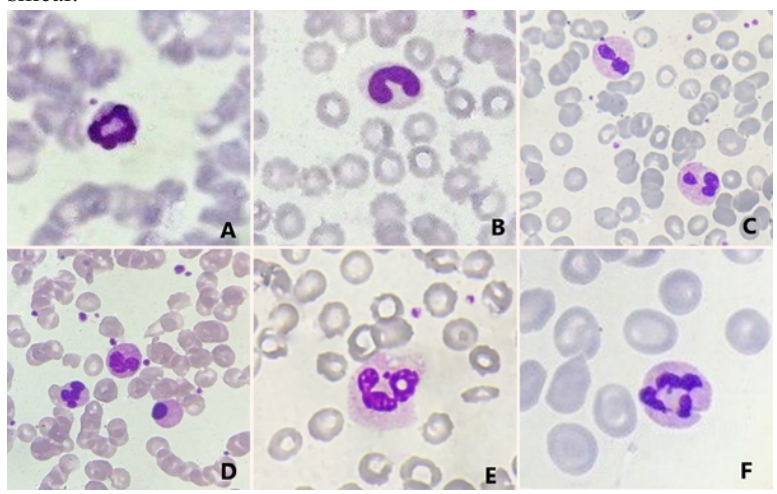

Figure 2 : Morphological abnormalities in Polymorphs.

A - ring shaped nuclei in polymorph , B - C shaped nuclei of polymorph, C - Hypolobated and hypogranular polymorphs, DApoptotic polymorph(arrow) with hypolobated polymorphs(arrow head) , E,F-Polymorphs with nuclear budding.

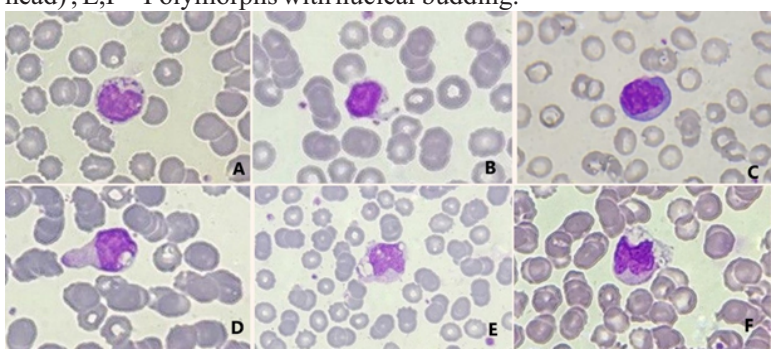

Figure 3 : Morphological abnormalities in Lymphocytes and Monocytes

A - Large granular lymphocytes, B- Large granular lymphocyte with pseudopod formation C-Reactive lymphocyte with dense basophilic cytoplasm, D - Reactive lymphocyte with cytoplasmic pseudopod formation, E,F - Monocytes with cytoplasmic vacuoles

\section{DISCUSSION}

Since the outbreak of COVID-19, there have been 9000-10000 new confirmed cases of COVID-19 every day in Maharashtra. The number of severe cases and deaths has also been increasing day by day. The current difficulty is the shortage of medical resources especially in critical cases. So early identification of critical ones and risk stratification will help and alleviate insufficient medical resources and might reduce mortality.

In study done by Fan BE et al, ICU patients were about a decade older than the non-ICU patients ${ }^{6}$. Similar findings were observed in our study. TLC $<4000 / \mu 1$ is considered as leucopenia and ALC $<1000 / \mu 1$ is considered as lymphopenia in our study. Eosinopenia is $\mathrm{AEC}<20 / \mu 1$ and Monocytopenia is AMC is $<200 / \mu l^{7}$. According to a study by Guan et al leucopenia and lymphopenia was associated with more severe disease ${ }^{8}$. A study by Deng Y et al shows similar findings ${ }^{9}$. Likewise, in our study leucopenia and lymphopenia was seen more in ICU and non-survivor patients. Lymphopenia was a major finding in our study which may be explained by various mechanisms. The coronavirus may directly infect the lymphocytes through the ACE2 receptor and may also directly destroy the lymphatic organs. Release of inflammatory cytokines may lead to lymphocyte apoptosis. Metabolic disorders such as hyperlactic acidemia produce various metabolic molecules which may inhibit lymphocytes ${ }^{10}$

In the present study, one of the major finding was eosinopenia which was comparable to the study done by Tanni $\mathrm{F}$ et $\mathrm{al}^{11}$. In our study the mean NLR was found to be higher among the ICU and non-survivors group than the Non-ICU group which was comparable to study done by Liu et $\mathrm{al}^{12}$. Increased NLR is associated with poor prognosis in various cancers. Similarly NLR can be used as a poor prognostic marker of COVID-19. There is significant difference of NLR between those who died of COVID-19 and recovered from COVID-19.

Major hematological findings like increasing NLR as well as lymphopenia is seen among the ICU groups and non-survivors. The severity of disease is observed more with increasing age. These hematological parameters should be closely monitored among all the COVID-19 patients from the day of admission and should be followed up during the course of disease as these abnormal findings may play a role of warning sign for upcoming worsening disease for the patient. With the disease progression, patients with severe disease showed lymphopenia with reduction of peripheral blood $\mathrm{T}$ Lymphocytes. Patients with severe disease were reported to have increased plasma concentration of proinflammatory cytokines. ${ }^{4}$ Uncontrolled secretion of cytokines of the innate immune system is associated with hyper inflammation and ARDS in COVID-19 patients ${ }^{13}$. Cardinal features of cytokine storm include unremitting fever, cytopenia, massive increases in ferritin, high ESR and Adult Respiratory Distress Syndrome (ARDS) ${ }^{14}$. Our study revealed an increase in ESR in all patients with higher values among the ICU patients than the Non-ICU group.

Our findings were comparable with study done by Singh A et al, which described the peripheral blood film findings in COVID-19. According to their study, neutrophils showed characteristic C-shaped, fetus-like nuclei, elongated nucleoplasm, and ring shaped nuclei. Large granular lymphocytes and activated monocytes was also described ${ }^{15}$. Weinberg $\mathrm{S}$ et al observed presence of atypical lymphocytes in most of their peripheral smears ${ }^{16}$. We also found presence of atypical lymphocytes in many patients.

Understanding the hematological parameters in COVID-19 infection is still in evolving stage. We present our findings which may help to better determine the prognostic factors and risk stratification.

\section{CONCLUSION}

COVID-19 has prominent impact on the hematopoietic system. Lymphopenia, higher NLR, Eosinopenia, Monocytopenia, Neutrophilia, raised ESR and morphologic alterations in leucocytes in peripheral blood film predict disease severity of the COVID-19 patients. All these findings are significant in ICU patients and nonsurvivors. Careful evaluation of these hematological parameters can assist clinicians in formulating treatment. In developing country like India, these may play a major role in risk stratification and alleviate the morbidity and mortality among COVID-19 patients with available resources.

\section{REFERENCES}

Zhu, N., Zhang, D., Wang, W., Li, X., Yang, B. \& Song, J. et al. (2020). A Nove Coronavirus from Patients with Pneumonia in China, 2019. The New England Journal Of Medicine, 382(8), 727-33.

http://www.covid19india.org/

3. Hussain, A., Kaler, J., Tabrez, E., Tabrez, S., \& Tabrez, S. (2020). Novel COVID-19: A 
Comprehensive Review of Transmission,
12(5). https://doi.org/10.7759/cureus. 8184 Evaluation and Treatment Coronavirus (COVID-19). In: StatPearls. StatPearls Evaluation and Treatment Coron

5. Terpos, E., Ntanasis.Stathopoulos, I., Elalamy, I., Kastritis, E., Sergentanis, T., \& Politou, M. et al. (2020). Hematological findings and complications of COVID.19. Am J Hematol, 95(7), 834-847. https://doi.org/10.1002/ajh.25829.

6. Fan, B.E., Chong, V.C.L., Chan, S.S.W, Lim, G.H., Lim, K.G.E., \& Tan, G.B. et al. (2020). Hematologic parameters in patients with COVID-19 infection. Am J Hematol, 95, E131-E153.https://doi.org/10.1002/ajh.25774

7. Bain, B., Bates, I., Laffan, M., \& Lewis, S. (2017). Dacie and Lewis Practical Haematology (12th ed., p. 11). Elsevier health sciences.

8. Guan, W., Ni, Z., Hu, Y, Liang,W., Ou, C. \& He, J., et al.(2020). Clinical characteristics of coronavirus disease 2019 in China. N Engl J Med. 382(18), 1708-1720. https://doi.org/10.1056/NEJMoa2002032

9. Deng, Y., Liu, W., Liu, K., Fang, Y.Y., Shang,J. \& Zhou, L., et al. (2020). Clinical characteristics of fatal and recovered cases of coronavirus disease 2019 in Wuhan, China: a retrospective study. Chinese Medical Journal. 133(11), 1261-1267. https://doi.org/10.1097/CM9.0000000000000824

10. Tan L, Wang Q, Zhang D, et al. Lymphopenia predicts disease severity of COVID-19: a descriptive and predictive study. Signal Transduct Target Ther 2020; 5:33

11. Tanni, F., Akker, E., Zaman, M.M Figueroa, N., Tharian, B., Hupart, K.H. (2020). Eosinopenia and COVID-19. J Am Osteopath Assoc, 120(8), 504-508. https://doi.org/10.7556/jaoa.2020.091

12. Liu, J., Liu, Y., Xiang, P., Pu, L., Xiong, H., \& Li, C. et al. (2020). Neutrophil-to-lymphocyte ratio predicts critical illness patients with 2019 coronavirus disease in the early stage. Journal of Translational Medicine, 206(18). https://doi.org/10.1186/s12967-020-02374-0

13. Johnson, B., \& Laloraya, M. (2020). A cytokine super cyclone in COVID-19 patients with risk factors: the therapeutic potential of BCG immunization. Cytokine And Growth Factor Reviews. https://doi.org/10.1016/j.cytogfr.2020.06.014

14. Mehta, P., McAuley, D., Brown, M., Sanchez, E., Tattersall, R., \& Manson, J. (2020). COVID-19: consider cytokine storm syndromes and immunosuppression. Lancet, 395(10229): 1033-1034 . https://doi.org/10.1016/S0140-6736(20)30628-0

15. Singh, A., Sood, N., Narang, V., \& Goyal, A. (2020). Morphology of COVID19-affected cells in peripheral blood film. BMJ Case Rep, 13:e236117. https://doi.org/10.1136/bcr-2020-236117

16. Weinberg, S., Behdad, A., \& Ji, P. (2020). Atypical lymphocytes in peripheral blood of patients with COVID-19. British Journal Of Haematology, 190, 24-39. 